\title{
University Students' Communication Skills as a Determinant of Academic Achievement
}

\author{
* Ashfaque Ahmad Shah (Corresponding Author) \\ ** Zunaira Fatima Syeda \\ *** Sehrish Naseer
}

\begin{abstract}
This study investigates into the academic achievement of university students as determined by their communication skills. The differences in groups were measured on the basis of gender, locality, semester and program of the study. The researchers developed their research instrument by adapting from the two questionnaires. One was the research instrument used at the College of Physiotherapists of Ontario (n.d.); and the other was the "Questionnaire-Verbal Communication" (Pierrete Desrosiers, n.d.). Taking Sargodha district as the population, conveniently sampled 160 students from the University of Sargodha were surveyed through the questionnaire. The study was quantitative in nature. The findings of the study concluded that students' communication skills yielded statistically no effect on their academic achievement. Also, the students at all levels (semesters) and in all programs were reported to have comparably equivalent level of communication skills. This is a unique study of insignificant differences at all levels and programmes; and statistically no interpretable effect of the communication skills of the students from University of Sargodha, on their academic achievement. It challenges previous research studies. It is further recommended to study the same phenomena in further detail to make decisive remark in the research literature.
\end{abstract}

Keywords: Academic achievement, Communication skills, University, Pakistan

Introduction

Communication is an act of transferring information. Communication skills include the ability to use language proficiently. These are the expertise that student have to practice themselves before they enter in the world of work (Iksan, et. al, 2011). Everyone wants to communicate effectively considering the purpose to share ideas and information. Mushtaq and Khan (2012) say that we cannot live without society, and to live in a society, we must have to communicate with others. For better and effective communication, we need these skills. Communication skills are the skills which everyone must have.

In our daily life activities, we need to communicate with others for different purposes. Students need such skills in completion of their degree because if they have such skills, they may present the ideas in an effective manner. Developing communication skills among students may benefit them in various aspects of their life -personal, social, professional etc. Expression is very important in every one's life; and effective communication skills are the basic element of best expression. Good communication is considered very important at all levels. Communication is a main tool to form relationships on the way to make more grounded relations among two individuals or a group of individuals. Without communication human relations are hard to be maintained. To be effective, a man needs an incorporated arrangement of communication skills. These abilities comprise composing ability, discourse abilities, listening aptitudes, and nonverbal aptitudes (Malohtra, n.d). During job interviews, the communication skills of new graduates do matter a lot. So, universities and staff need to make sure if the learners are trained in the skill to talk efficiently. The students should develop their communication skills in a broad as well as inclusive way. Students actually have to extend their expertise to do well within their chosen occupation (Ihmeideh, et al. 2010).

Communication skills include the ability to use language proficiently. These are the abilities

\footnotetext{
* Centre for Economics of Education, Department of Education, University of Sargodha, 40100, Sargodha, Pakistan Email: multanxa@gmail.com

** Centre for Economics of Education, Department of Education, University of Sargodha, 40100, Sargodha, Pakistan Email: zunaira.fatima@uos.edu.pk

*** Centre for Economics of Education, Department of Education, University of Sargodha, 40100, Sargodha, Pakistan Email: sehrishnwarraich@gmail.com
} 
that student must prepare themselves earlier than they go into the world of work (Iksan et. al, 2011). Such abilities are important in helping students to perform well academically (Iksan et. al, 2011). Academic achievement is the result of learning; the degree to which a learner has accomplished their learning objectives. The learners' academic achievement assumes an essential element producing excellent quality graduates capable to be awesome pioneer (Mushtaq \& Khan, 2012). Academic achievement prepares students for their future success in both education as well as the world of work. Academic achievements the performance of a student and usually measured in the term of Cumulative Grade Point Averages i.e. CGPAs (Ali, 2009).

It was perceptible to believe that the communication skills were having very positively deterministic role on the academic achievement of the university students. The research literature was found replete with the results that confirm positive impact of the communication skills on the academic achievement of students especially at university level. However, it is always probable to believe that these results would have been challenged by some researchers in different geographical locations. Such challenges add always to the status of a scientific theory. Karl Poppers' theory of falsification is an excellent way to believe such challenging findings. According to his theory of falsification, a theory cannot be scientific unless it is falsifiable. If it is not falsifiable, it is no more a scientific theory. We are not going to dive deeper into the theory of falsifiability here in this paper. We intended to only prepare the researchers and the readers understand the unusually challenging findings in research perspectives.

Several studies have been reported in the field of communication skills, reporting their positive effect on the academic achievement of students. The present research investigated into the university students' academic achievement under the effect of their communication skills. The result from this study provided valuable information about communication skills to students in many ways. This would be beneficial to all the stakeholders including teachers, parents, policy makers etc.

\section{Review of Literature}

Inner Social Course (ISC) and Outer Social Course (OSC) are the two main factors influencing the student's academic achievement (Mushtaq \& Khan, 2012). The former factors contain student's English language competence, class-plans, class-size, the textbooks, test-results, learning-facilities, home-assignments, class-environment, course-material problems, in-class instructor's role, innovations used in the class, and exams-plan. The later factors contain for example parents' occupation, and plethora of social, professional and financial dimensions.

Research literature demonstrated that students' academic achievement was the outcome of various factors, for example, personnel, sex, age etc etc. Abdullah AL Mutairi (2011) maintained that the students' academic achievement heavily depended upon their previous learning and especially their level of communication skills in English Language and this had conclusively been evidenced in the literature. As cited by Iksan (2011) in general, communication is explained as exchanging information between the individuals through verbal and non- verbal ways. All the changes in society are hinged upon (Mahmud, 2013) the studies in communications and verbal ability of the individuals.

The accurate use of communication, additionally, encourages good quality relationship. Not just can dialect and discourse test influence one's learning capacities, it also influences the public capacities, for example, making friends, increasing healthy connections, as well as accomplishing a boosted self-assurance. This self-assurance might help student in putting additional attempt for executing fine. A student of university, being prepared for a profession, perceives communication skills in broader perspective, and believes that such abilities are vital and should be developed systematically (Muhmud, 2013).

Learners necessitate placing effort to build up their communication skills to have the capacity to do well in their chosen professions (Ihmeideh, 2010). Mushtaq \& Khan (2012) said that the universities, in fact, enclose no value to a student; rather, the students are the most important resources for an institute of higher education. Societal as well as financial advancement of a state relies on university students; and deeply tied to their academic achievement. Student's academic achievement becomes an essential element in defining individual as well as public development (Ali, 2009). Students' academic achievement has received high attention in the research literature. Student performance is observed to be deeply dependent upon the communication skills.

As indicated by Brockman \& Russell (2012) that the students of $21^{\text {st }}$ century had a clear target of making educational progress; and they are focussed on developing abilities, including 
communication skills. University students' academic achievement is evidenced directly through their CGPAs.

\section{Methodology}

This section addressed methodology of research. According to Leedy and Ormrod (2001), research methodology is "the common approach the researcher uses for execution of the research project". Present research was to study the effect of the communication skills on the students' academic achievement (CGPAs) at university level. Following procedures were adapted for this study.

This part described the strategies of data collection, the research procedure and the technique of sampling that was utilized to choose the respondents of the study. Quantitative research technique was used to analyse the data.

It was a descriptive research. Survey method was used. In this study the researchers administered a survey through an adapted questionnaire to a small group of people (sample) to see the tendency in attitude, views, behaviours, or other attributes of a large group of people (Creswell, 2012 a). The population of the study includes all the student of BS, BEd, MA, and MPhil program in main and the sub campuses of the university. Accessible population was the main campus students. The researchers personally collected data from 160 male and female students of BS, BEd, MA, and MPhil from the University of Sargodha. Researchers carefully self-administered the questionnaires to conveniently accessible sample (as suggested by Gay \& Mills, 2011) in order to collect the data. The researchers developed their research instrument by adapting the questionnaires from two studies. One was (http://www.collegept.org/Assets/Resources\%20\%20QM/QMF_Skills_ LearningQuestionnaire.pdf) used at the College of Physiotherapists of Ontario; and the other instrument was the "Questionnaire-Verbal Communication" by (http://www.collegept.org/Assets/Resources\%20\%20QM/QMF_Skills_Learning Questionaire.pdf) Pierrete Desrosiers (n.d.) .

This instrument appeared to be more suitable as it was simple to answer. A five point Likert scale was used having the options of SA (strongly Agree), A (Agree), UN (Undecided), DA (Disagree) and SD (Strongly Disagree). Pilot study was conducted to estimate the internal consistency of the questionnaire. Questionnaires were administered to the small number of the conveniently selected sample. To determine reliability, the data thus collected were analysed on computer by SPSS. The reliability of the data was found to be 0.600 .

Finally, the collected data were analysed through descriptive (frequency, mean, median, mode, variance, Standard Deviation) and inferential techniques (t-test, Analysis of Variance and linear regression) using SPSS. The values of t-test (independent samples) helped understand the differences in gender and locality of the university students; the One-Way ANOVA helped understand the difference among students of different semesters and programs of the university; and the linear regression estimated the effect of the communication skills (predictors) on the academic achievement (outcome) of university students. Researcher used following equation of linear regression.

$$
\boldsymbol{Y}=\boldsymbol{\alpha}+\boldsymbol{\beta} \boldsymbol{X}+\boldsymbol{\varepsilon}
$$

$Y$ represents academic achievement $\alpha$ represents intercept, $\beta$ i s the coefficient of $X$ which represents communication skills, and the value of $\beta$ denote the effect size of the predictor on the academic achievement.

\section{Results}

This section presented analyses as well as interpretation of the data. Major purpose of the study was to find out the effect of communication skills of university students on their academic achievement. This section has two parts i.e. analysis through descriptive and inferential statistic communication skills.

Table 1: Gender wise distribution of the sample

\begin{tabular}{cl}
\hline Gender & Frequency $(\boldsymbol{\%})$ \\
\hline Male & $59(36.9)$ \\
Female & $90(56.2)$ \\
\hline Not mentioned & $11(06.9)$ \\
\hline Total & $\mathbf{1 6 0}(100)$ \\
\hline
\end{tabular}

In descriptive part of statistic communication skills, explanation of the sample is discussed while testing of the hypothesis and understanding of the consequences are specified in inferential part 
of this chapter. Frequencies and percentages of the responses were recorded as under.

Table 1 showed that total respondents of the study comprising 59 male students and 90 female students. Among the respondents, $37 \%$ were the males and $56 \%$ were the females.

Table 2: Locality wise distribution of the sample

\begin{tabular}{cc}
\hline Locality & Frequency (\%) \\
\hline Urban & $96(60)$ \\
Rural & $64(40)$ \\
\hline Total & $\mathbf{1 6 0}(100)$ \\
\hline
\end{tabular}

Table 2 explained that out of 160 university students 96 were from urban areas while 64 were from rural areas. On the whole $60 \%$ students were from urban locality while $40 \%$ students were from rural locality.

Table 3: Semester wise distribution of the sample

\begin{tabular}{ccc}
\hline Semester & Frequency & Percentage \\
\hline $\mathbf{1}$ & 03 & 01.9 \\
$\mathbf{2}$ & 76 & 47.5 \\
$\mathbf{4}$ & 43 & 26.9 \\
$\mathbf{5}$ & 01 & 00.6 \\
$\mathbf{6}$ & 24 & 15.0 \\
$\mathbf{8}$ & 13 & 08.1 \\
\hline Total & $\mathbf{1 6 0}$ & $\mathbf{1 0 0 . 0}$ \\
\hline
\end{tabular}

Table 3 showed that out of 160 university students, $3(1.9 \%)$ students were from $1^{\text {st }}$ Semester, $76(47.5 \%)$ from $2^{\text {nd }}$ Semester, $43(26.9 \%)$ from $4^{\text {th }}$ Semester, $1(0.6 \%)$ from $5^{\text {th }}$ semester, $24(15.0 \%)$ from $6^{\text {th }}$ Semester and $13(8.1 \%)$ from $8^{\text {th }}$ semester of their study program.

Frequencies and percentages of the responses were produced in the following table.

Table 4: Programme wise distribution of the sample

\begin{tabular}{ccl}
\hline Program & Frequency & Percent \\
\hline BS & 75 & 46.9 \\
Masters & 71 & 44.4 \\
BEd & 4 & 2.5 \\
MPhil & 10 & 6.2 \\
\hline Total & $\mathbf{1 6 0}$ & $\mathbf{1 0 0 . 0}$ \\
\hline
\end{tabular}

Table 4 showed that out of 160 university students, 75(46.9\%) students were from BS program, 71(44.4\%) students were from master's program, 4(2.5\%) students were from B.Ed. program and 10(6.2\%) students were from MPhil program.

Table 5: indicator wise frequency and percentage response of the Sample

\begin{tabular}{lccccc}
\hline Communication Skills & SA & A & UD & DA & SD \\
\hline 1. Paraphrasing of words & 18 & 108 & 21 & 08 & 05 \\
& $(11.2)$ & $(67.5)$ & $(13.1)$ & $(5.0)$ & $(3.1)$ \\
2. Ability to present ideas orally & 41 & 79 & 25 & 14 & 01 \\
& $(25.6)$ & $(49.4)$ & $(15.6)$ & $(8.8)$ & $(0.6)$ \\
3. Ability to communicate effectively & 38 & 90 & 23 & 08 & 01 \\
& $(23.8)$ & $(56.2)$ & $(14.4)$ & $(5.0)$ & $(0.6)$ \\
4. Writing error free grammatical report & 16 & 71 & 39 & 26 & 08 \\
& $(10.0)$ & $(44.4)$ & $(24.4)$ & $(16.2)$ & $(5.0)$ \\
5. Ability to verbally comprehend the messages & 24 & 79 & 41 & 13 & 03 \\
& $(15.0)$ & $(49.4)$ & $(25.6)$ & $(8.1)$ & $(1.9)$ \\
6. Absorbing written material quickly & 27 & 73 & 40 & 18 & 02 \\
& $(16.9)$ & $(45.6)$ & $(25.0)$ & $(11.2)$ & $(1.2)$ \\
7. Cooperation with peer group & 83 & 67 & 07 & 01 & 02 \\
& $(51.9)$ & $(41.9)$ & $(4.4)$ & $(0.6)$ & $(1.2)$ \\
8. Paying attention to nonverbal cues & 35 & 67 & 32 & 22 & 03 \\
& $(21.9)$ & $(41.9)$ & $(20.0)$ & $(13.8)$ & $(1.9)$
\end{tabular}




\begin{tabular}{|lccccc} 
9. Acceptance of criticism & 34 & 77 & 31 & 11 & 07 \\
& $(21.2)$ & $(48.1)$ & $(19.4)$ & $(6.9)$ & $(4.4)$ \\
10. Ability to bear criticism calmly & 28 & 84 & 32 & 13 & 03 \\
& $(17.5)$ & $(52.5)$ & $(20.0)$ & $(8.1)$ & $(1.9)$ \\
11. Expressing disagreement & 31 & 68 & 40 & 17 & 04 \\
& $(19.4)$ & $(42.5)$ & $(25.0)$ & $(10.6)$ & $(2.5)$ \\
12. Encouraging others for clarification of their thoughts & 38 & 91 & 18 & 11 & 02 \\
13. Acceptance of suggestions at workplace & $(23.8)$ & $(56.9)$ & $(11.2)$ & $(6.9)$ & $(1.2)$ \\
& 40 & 82 & 22 & 13 & 03 \\
& $(25.0)$ & $(51.2)$ & $(13.8)$ & $(8.1)$ & $(1.9)$ \\
\hline
\end{tabular}

Table 5 showed that the university students did possess good level of communication skills. It described various sub-indicators in the communication skills.

It was comprehensive to know that large majority of the participants agreed (and strongly agreed) on all the thirteen sub-indicators showing their propensity towards higher achievement of communication skills. Conversely, there was lesser number of participants expressing their disagreement (including strong disagreement). Number of undecided participants on the various sub-indicators was really of some concern, particularly, the following four subindicators, namely, writing error free grammatical report, ability to verbally comprehend the messages, absorbing written material quickly, and expressing disagreement. Their indecision on these sub-indicators may have serious implications on the overall research findings. The researchers were prudent in this regard. It is also important to note those participants who remained undecided.

Table 6: Descriptive Statistic of the Sample

\begin{tabular}{|c|c|c|c|c|c|}
\hline Communication Skills & Mean & Median & Mode & SD & Variance \\
\hline 1. Ability to paraphrase words & 2.2 & 2.2 & 2.0 & 0.8 & 0.7 \\
\hline 2. Presentation of oral ideas & 2.1 & 2.0 & 2.0 & 0.9 & 0.8 \\
\hline 3. I have ability to communicate effectively and appropriately & 2.0 & 2.0 & 2.0 & 0.8 & 0.6 \\
\hline 3. Ability to communicate effectively & 2.6 & 2.0 & 2.0 & 1.0 & 1.1 \\
\hline 4. Writing error free grammatical report & 2.3 & 2.0 & 2.0 & 0.9 & 0.8 \\
\hline 5. Ability to verbally comprehend the messages & 2.3 & 2.0 & 2.0 & 0.9 & 0.9 \\
\hline 6. Absorbing written material quickly & 1.6 & 1.0 & 1.0 & 0.7 & 0.5 \\
\hline 7. Cooperation with peer group & 2.6 & 2.0 & 2.0 & 3.5 & 11.9 \\
\hline 8. Paying attention to nonverbal cues & 2.3 & 2.0 & 2.0 & 1.0 & 1.0 \\
\hline 9. Acceptance of criticism & 2.2 & 2.0 & 2.0 & 0.9 & 0.8 \\
\hline 10. Ability to bear criticism calmly & 2.3 & 2.0 & 2.0 & 1.0 & 1.0 \\
\hline 11. Expressing disagreement & 2.1 & 2.0 & 2.0 & 0.9 & 0.7 \\
\hline 12. Encouraging others for clarification of their thoughts & 2.1 & 2.0 & 2.0 & 0.9 & 0.9 \\
\hline 13. Acceptance of suggestions at workplace & 2.1 & 2.0 & 2.0 & 0.9 & 0.9 \\
\hline
\end{tabular}

In Table 6, mean, median, mode (measures of central tendency), standard deviation and variance (measures of dispersion) were represented. The range of all the statements is " 4 ". This table comprehensively described the data we were using in this piece of research.

The measures of central tendency reflected that data thus collected showed a very slight deviation of behaviour from the normal curve. Ideally, Mean $=$ Median $=$ Mode; in present research study Mean $>$ Median $=$ Mode. This revealed very slight positive skewness. One sub-indicator (Absorbing written material quickly) exhibited a behaviour of an outlier; nevertheless, following the same pattern of Mean $>$ Median $=$ Mode.

The measure of dispersion i.e. Standard Deviation (SD), was found around 1, except only one sub-indicator i.e. Cooperation with peer group. It also confirmed the normal behaviour of the collected data if compared to the normal curve. Such behaviour, as observed in our data set, lent credibility to our analyses through the data we had collected.

Table 7: Gender Difference

\begin{tabular}{lcccccc}
\hline Gender & N & Mean & SD & SE Mean & t & P \\
\hline Female & 90 & 30.766 & 7.060 & 0.74419 & 0.313 & 0.803 \\
Male & 59 & 31.135 & 7.006 & 0.91211 & \\
\hline
\end{tabular}


In Table 7 the value of $t=0.313$ and $\mathrm{P}=0.803$, illustrated that there was insignificant difference between both male and female students. Putting the same in other words, both male and female students had had a similar level of communication skills.

In Table 8 the value of $\mathrm{t}=1.402$ and $\mathrm{P}=0.054$ demonstrated that there was insignificant difference regrading locality background of the students. In other words, the students having urban and rural family background had had a comparable level of communication skills.

Table 8: Locality Difference

\begin{tabular}{lcccccc}
\hline Locality & N & Mean & SD & SE Mean & t & P \\
\hline Urban & 96 & 31.447 & 7.8711 & 0.8033 & \multirow{2}{*}{1.402} & 0.054 \\
\hline Rural & 64 & 29.906 & 4.8064 & 0.60081 & & \\
\hline
\end{tabular}

In Table 9 the value of $F(27,132)=1.072$ and $\mathrm{P}=0.382$ explained that there was insignificant difference among the communication skills of students from different semesters.

Table 9: Semester wise difference

\begin{tabular}{llcccc}
\hline & Sum of Squares & Df & Mean Squares & F & P \\
\hline Within Groups & 503.137 & 132 & 3.812 & 072 & 0.382 \\
\hline Between Groups & 110.363 & 27 & 4.088 & & \\
\hline Total & 613.500 & 159 & & & \\
\hline
\end{tabular}

Similar level of communication skills had been noted among students of all the programmes.

Table 10: Programme wise difference

\begin{tabular}{llcccc}
\hline & Sum Squares & Df & Mean Squares & \multirow{2}{*}{ F } & Sig \\
\hline Within Groups & 90.998 & 132 & 0.689 & 0.631 & 0.918 \\
\hline Between Groups & 11.745 & 27 & 0.435 & & \\
\hline Total & 102.744 & 158 & & & \\
\hline
\end{tabular}

In Table 10 the value of $\mathrm{F}(27,132)=0.631$ and $\mathrm{P}=0.918$ indicated that there was insignificant difference; and therefore, equivalent level of communication skills was noted for the students from all the programs.

Following was the regression equation to estimate the effect of communication skills on the academic achievement of university students.

$$
Y=\alpha+\beta X+\varepsilon
$$

$\mathrm{Y}$ represents academic achievement, $\alpha$ represents the intercept, $\beta$ is the coefficient of $\mathrm{X}$ i.e. communication skills. The value of $\beta$ represented the effect size of the communication skills (predictor). Details about effect of communication skills on academic achievement were described below.

Table 11: Summary of the Model

\begin{tabular}{cccc}
\hline $\mathbf{R}$ & $\mathbf{R}^{2}$ & Adjusted $\mathbf{R}^{2}$ & SE \\
\hline 0.091 & 0.008 & 0.002 & 1.031 \\
\hline
\end{tabular}

The value of $\mathrm{R}^{2}$ indicated that the model was very weak to explain the variance in the dependent variable (i.e. academic achievement) under the effect of the independent variable (i.e. communication skills). Details about impact of communication skills on academic achievement were presented as below.

Table 12: Impact of Communication Skills

\begin{tabular}{|c|c|c|c|c|c|}
\hline & \multicolumn{2}{|c|}{ Unstandardized } & \multirow{2}{*}{$\begin{array}{c}\text { Standardized } \\
\text { B }\end{array}$} & \multirow{2}{*}{$\mathbf{t}$} & \multirow{2}{*}{$\mathbf{P}$} \\
\hline & $\beta$ & $S E$ & & & \\
\hline $\begin{array}{l}\text { Constant } \\
\text { Communication Skills }\end{array}$ & $\begin{array}{c}2.985 \\
-0.014\end{array}$ & \begin{tabular}{l|}
0.378 \\
0.012
\end{tabular} & -0.091 & $\begin{array}{l}.904 \\
-1.145\end{array}$ & $\begin{array}{l}0.000 \\
0.254\end{array}$ \\
\hline
\end{tabular}

In Table 12 the value of $\mathrm{P}=0.254$ illustrated that there was insignificant difference and therefore the null hypothesis (There was no statistically significant effect of communication skills on 
academic achievement) was failed to be rejected. Students' communication skills had not been found making any regular and systematic impact on their academic achievement.

\section{Discussion and Conclusion}

Communication skills include the ability to use language efficiently. These are the abilities that student must equip themselves before entering into their professional life (Iksan, et. al, 2012). Such skills are important in helping students perform well academically as well. These are the skills required by all the students irrespective of gender and locality of their residence. Present research confirmed the same truth for the students from different semesters and different programmes studying at University of Sargodha, Pakistan. Iksan, et. al. (2012) found that students of university had achieved good level of communication skills.

It was found that the communication skills of rural boys and girls were much less than those of their urban counterparts (Tabish \& Iqbal, 2015). These results were challenged by the present study which reported insignificant difference among students both males and females from different locality back grounds.

Fazel \& Aghamolaei (2011) revealed statistically insignificant gender difference among students regarding their communication skills. Present research study revealed the same phenomenon of insignificant difference between male and female students. Our study confirmed what other researchers (for example, Fazel \& Aghamolaei, 2011) had discovered previously.

We found that communication skills had no effect on the academic achievement of the university students in our data set. Differing with the findings of the current research, other researchers had indicated that achieving proficiency in verbal communications is essential to students to do good academically (Mahmud, 2014).

We conclusively revealed that the communication skills were found to be alike among male/female and urban/rural university students. Similarly, the students at all levels (semesters) and in all programmes were reported to be possessed of comparable level of communication skills. The unusual finding of no effect of communication skills on the academic achievement of university students in present research has challenged previously known positive deterministic relationship of the two variables. Further deeper analyses may help understand the perceptible phenomenon more lucidly.

\section{Recommendations}

Present research had been delimited to one university which we as the researchers consider as the major challenge. Although, within this we tried to accommodate a diversified sample with respect to gender, locality of residence as a background of the family of the students, all the semesters from various study programmes.

It was therefore suggested that a larger and more diversified sample would have yielded more robust results thus a reliable picture of the outcome. It was recommended that future researcher should make use of other variables to observe the relationship between academic achievement and communication skills. Mediating and/or moderating impact of different other variables would be offering better context of the results. Similar study should be carried out at other universities to get more comprehensive representation of the participants in the sample. The reliability of research instrument was 0.600; it was recommended for further studies that the researchers should carry out item analysis before adaptation of the research instrument(s).

\section{References}

Ali, N., Ali, S., Mokhtar, N., \& Salamat, A. S. (2009). The Factors Influencing Students' Performance, Management Science and Engineering, 2 (3).

Fazel, I., \& Aghamolaei, T. (2011). Attitude towards learning communication skills. Acta Medica Iranica, 3 (4).

Gay, L. R., \& Mills, G. E. (2011). Educational Research; competencies for analysis. New York: Pearson.

Ihmeideh, F. M., Al-Omari, A. A., \& Al-Dababneh, K. A. (2010). Attitudes toward communication skills among Students-Teachers in Jordanian Public Universities. Australian Journal of Teacher Education, 3 (1).

Iksan, Z. H., Zakaria, E., Meerah, T. S., Osman, K., Lian, D. K., Mahmud, S. N. (2011). Communication skills among university students, Procedia-Social and Behavioral Sciences, 2 (3). 
Leedy \& Ormrod, 2001, retrieved On June 14, 2016 from https://www.google.com.pk/search?q=Leedy+\%26+Ormrod\%2C+2001\%29\%2C+research+m ethodology\&oq=Leedy+\%26+Ormrod $\% 2 \mathrm{C}+2001 \% 29 \% 2 \mathrm{C}+$ research+methodology\&gs_l=ser p.3...749256.753366.0.753836.16.7.0.0.0.0.343.343.3-1.1.0...0...1c.1j2.64.serp..15.0.0. QHkp f8rxP1g.

Mahmud, M. M. (2013). Communication aptitude and academic success. Procedia social and behavioral sciences, 2(4).

Mahmud, M. M. (2013). Communication aptitude and academic success. Procedia - Social and Behavioral Sciences, 134 (2014).

Mushtaq, I., \& Khan, S. N. (2012). Factors Affecting Students Academic performance. Global Journal of Management and Business Research, 2 (3).

Mutairi, A. A. (2011). Factors Affecting Business Students' Performance in Arab Open University: The case of Kuwait. International Journal of Business and Management, 6 (5).

Questionnaire-verbal communication (Desrosiers) was accessible on the following URL: http://pierrettedesrosiers.com/documents/QUEST_verbal_communication_JG_001.pd.

Russell, C. D. (2012). Gender, Academic Achievement, and Meanings of Schooling in Ras al Khaimah, United Arab Emirates. Unpublished Thesis, Columbia University.

Skills for Learning Questionnaire (College of Physiotherapists of Ontario), was accessible on the following URL: http://www.collegept.org/Assets/Resources\%20\%20QM/QMF_Skills_ LearningQuestionaire.pdf.

Tabish, M., \& Iqbal, T. (2015). English Language Learning Proficiency of Rural Learner Compared to Urban: a Case Study of Management Students. Journal of Science \& Management, 2 (3). 